\title{
The Dark Side of Emotional Intelligence
}

\author{
Adrian Furnham ${ }^{1,2}$, Adrienne Rosen 1 \\ ${ }^{1}$ Department of Clinical, Educational, and Health Psychology, University College London, London, UK \\ ${ }^{2}$ Norwegian Business School (BI), Nydalveien, Olso, Norway \\ Email: a.furnham@ucl.ac.uk
}

Received 4 January 2016; accepted 21 March 2016; published 24 March 2016

Copyright (C) 2016 by authors and Scientific Research Publishing Inc.

This work is licensed under the Creative Commons Attribution International License (CC BY). http://creativecommons.org/licenses/by/4.0/

(c) (i) Open Access

\begin{abstract}
Over 300 British adults completed the Hogan Development Survey (HDS) (Hogan \& Hogan, 2001), a measure of the personality disorders and the Bar-On Emotional Quotient Inventory (EQi) (BarOn, 2004). Work associates known to the participants also completed an observers' version of the EQi. The structures of both inventories were examined. The HDS factored into three clear factors (clusters A, B, C) confirming previous analyses while the EQi had a single factor structure. Cluster B disorders (labelled Moving Against People) were correlated negatively with the Stress scale on the EQi while Cluster A disorders (labelled Moving Away from People) were negatively correlated with Intrapersonal, Interpersonal and Mood subscale scores on the EQi. Regressions showed that Avoidant, Schizoid and Narcissistic disorders most consistently related to the self-reported EQi subscale scores. Interestingly Paranoia was positively correlated with the total and the Intrapersonal EQi scores. Participants tended to have higher self, compared to observer scores on the EQi. Only one regression was significant: participants with lower Borderline and Schizotypal scores were seen to be better at Stress management.
\end{abstract}

\section{Keywords}

Emotional Intelligence, Personality Disorders, 360 Degree Feedback

\section{Introduction}

This study is concerned with emotional intelligence (EI) correlates of dysfunction work personality traits. There is an extensive empirical literature relating EI to a wide range of behaviours related to interpersonal relationships, health and education (Furnham, 2008). In most studies EI is to be considered a very positive trait or ability (depending on how it is conceived) and something that has numerous behavioural benefits.

Zeidner, Matthews, \& Roberts (2004) provided a useful critical overview of the role of EI in the workplace. They argue that if EI does predict satisfaction, productivity, teamwork etc., the question is what is the process or 
mechanism that accounts for this? Ideas include high EI people that are better at communicating their ideas, intentions and goals. They are more articulate, assertive and sensitive. Also EI is closely associated with teamwork and social skills. Possibly business leaders, high in EI, build supportive climates that increase organisational commitment which in turn leads to success (Furnham, 2008).

Another possibility is that high EI managers/leaders are perceptive and know their own and their teams' strengths and weaknesses which enable them to leverage the former and compensate for the latter. Also EI is related to effective and efficient coping skills that enable people to deal with demand, pressure and stress better. It could be that high EI managers/leaders can accurately identify what followers feel and need, as well as, being more inspiring and supportive. Finally high EI managers, unlike their low EI companions, are less prone to negative, defensive and destructive coping and decision-making styles.

EI is conceived as a continuum from low to high. Those who score very low are thought to be alexithymic which is defined as difficulty in identifying and describing subjective feelings, a poor imagination and an externally oriented style of thinking (Petrides, Hudry, Michalaria, Swami, \& Sevdalis, 2011). They are poor at emotional identification, regulation and responses (Singh, Artche, \& Holder, 2011). Indeed Parker, Taylor, \& Bagby (2001) demonstrated that EI and alexithymia are strongly and inversely related. Low scores are also associated with addictions (Demetrovics, 2010). It seems reasonable to assume the low EI scores would be associated with Schizoid and Avoidant personality disorder (PDs) given the research that looks at the association between personality types, traits and disorders (Furnham \& Crump, 2005).

This study used two EI measures: a self-report measure and the 360 measure where different raters-typically a manager (boss), peers, direct reports and others rate a specific person. This generates the same aggregated scores as the self-report measure. One issue that this study will consider is the relationship between the self- and other-rated scores. It is anticipated that the scores will be modestly correlated (around $r=0.30$ ) but that there will be evidence of a self-inflationary effect such that participants' scores are significantly higher than those of the raters (Petrides, Niven, \& Mouskounti, 2006).

This study is also concerned with the relationship between EI and the "dark side" PDs (Martins, Ramalho, \& Morin, 2010; Petrides, Perez-Gonzalez, \& Furnham, 2007; Petrides et al., 2011). Over the past 10 years, various popular books have been written that describe the disorders in lay-terms. Many are self-help books written by psychologists and psychiatrists in attempting to educate the public about them. Writers have changed the names to make them more "understandable" (Dotlich \& Cairo, 2003; Oldham \& Morris, 1991). These PDs are grouped along different axes or clusters, usually the following three: A) Odd/Eccentric (Paranoid, Schizoid, Schizotypal); B) Dramatic/Emotional/Erratic (Antisocial, Borderline, Histrionic, Narcissistic) and C) Anxious/Fearful (Avoidant, Dependent and Obsessive-Compulsive). These three clusters have also been described as Moving Against (A), Moving Toward (B), and Moving Away from (C) others (Hogan \& Hogan, 1997).

There are various self-report measures available to assess PDs. This study is based on the Hogan "dark side" measure now extensively used in organisational research and practice to measure PDs in the "normal population" (Hogan \& Hogan, 2001). Its aim is partly to help selectors and individuals themselves diagnose how they typically react under work stress.

The Hogan Development Survey (HDS) is based on PD categories, and used as a "normal" measure of dysfunctional personality at work. The HDS focuses only on the core construct of each disorder from a dimensional perspective (Hogan \& Hogan, 2001: p. 41). An overview of the item selection guidelines can be found in Hogan \& Hogan (2001). The HDS has been cross-validated with the MMPI PD scales. Correlations $(N=140)$ range from 0.45 for Antisocial to 0.67 for Borderline (Hogan \& Hogan, 2001).

Fico, Hogan, \& Hogan (2000) report coefficient alphas for the HDS between 0.50 and 0.70 with an average of 0.64 and test-retest reliabilities $(N=60)$ over a three-month interval ranging from 0.50 to 0.80 , with an average of 0.68 . There were no mean-level differences between sexes, racial/ethnic groups, or younger versus older persons (Hogan \& Hogan, 2001). Various relatively small-scale studies have used the HDS and have shown it to be a robust, reliable and valid instrument (De Fruyt et al., 2009; Furnham, 2006; Furnham \& Crump, 2005; Khoo \& Burch, 2008; Rolland \& De Fruyt, 2003). One recent study on a population exceeding 18,000 showed a clear structure for the instrument with the three-fold classification established except Cluster A was called Moving Away from People, Cluster B was called Moving Against People and Cluster C just Diligent (Furnham \& Trickey, 2011).

There have been a few studies on the relationship between EI and the PDs (Martin et al. 2010; Petrides et al., 2007), but none have used the measures of EI or the PDs used in this study. 
Leible \& Snell (2004) looked at the relationship between the Cluster A, B and C PDs (as measured by the Personality Diagnostic Questionnaire-4+ (Hyler, 1994) and a three dimensional measure of emotional awareness (Snell, 1999) in a large student sample. However both not very well known measures of either construct and rarely used in research. The data of 10 disorders and three EI scores (emotional clarity, emotional attention, emotional regulation) showed 23 of the correlations negative (with only one $r>0.05$ ) and one being significant positive (Histrionic and Emotional Attention: $r=0.12$ ). The PDs were most strongly and consistently (negatively) related to emotional clarity (rumination about personal emotions) and least with emotional attention (being aware of, concerned with and attention to personal emotions). They were particularly interested in Borderline PD, which showed one on the highest (negative) correlations with their measure of EI.

Aguirre, Sergi, \& Levy (2008) found persons high in schizotypy were impaired in overall EI, particularly the ability to perceive and manage emotions, as well as peer and family relationships and academic functioning. Gardner \& Qualter (2009) found, as predicted, a negative relationship between EI and Borderline PD. Using both multidimensional trait and ability EI measures they found the strongest (negative) correlates of emotion were the perceptions and management of emotions. Their results showed that none of the subfactors of EI were significantly related to Borderline PD which suggests the advisability of the use of multidimensional measures.

This study is concerned with which, and how much, the PDs are related to self- and other-rated EI. One way of deriving hypotheses is to examine the literature on the relationship between EI and the Big Five Personality Traits and the relationship between the Big Five and the PDs. Many studies have examined Big Five correlations of EI scores at both total and facet level and have tended to show that all five factors are related to EI but particularly Emotional Stability, Extraversion and Conscientiousness (Vernon, Villani, Schermer, \& Petrides, 2008). Studies have also looked at big five correlates of the PDs. Furnham \& Crump (2005) showed Neuroticism most strongly correlated with Borderline (Excitable) and Avoidant (Cautious) PD; Extraversion with Avoidant and Schizoid (Reserved) and Conscientiousness with Dependent (Dutiful). No direct hypotheses were derived as this study was exploratory however it was assumed based on the above literature that the relationship between the PDs and the EI subscales would be significantly negative, particularly with respect to Avoidant, Borderline and Schizoid PD.

\section{Method}

\subsection{Participants}

In all 329 people took part of whom 301 were males. They ranged in age from 30 to 50 years old. They were all working Britons predominantly working in IT, financial services and in assurance. All were participants on a senior leadership development programme.

\subsection{Measures}

Bar-On Emotional Quotient Inventory (Bar-On, 2004). The Emotional Quotient Inventory (EQ-i), EQ-360 \& EQ-i: YV. Different versions were developed to assess the Bar-On model of emotional-social intelligence. The EQ-I is a self-report measure designed to measure a number of constructs related to EI. The EQ-i consists of 133 items and takes approximately 30 minutes to complete. It gives an overall EQ score as well as scores for the five composite scales and 15 subscales (Bar-On, 2004, 2006). The measure has been used in many studies (Butler \& Chinowsky, 2006; Day, Therrin, \& Carrol, 2005; Dawda \& Hart, 2000). The EQ-360 is an observer version which is used in 360 feedback situations. In this study around 3 - 6 people (boss, peers and subordinates) rated the person who they knew well. It was possible to get a single mean observers score per person.

Hogan Development Survey (Hogan \& Hogan, 1997). The survey includes 154 items, scored for 11 scales, each grouping 14 items. Respondents are requested to "agree” or "disagree” with the items. The HDS has been cross-validated with the MMPI PD scales as well as "normal traits" (Furnham \& Crump, 2005). The measure has been used in many studies (DeFruyt et al., 2009; Furnham \& Trickey, 2011).

\subsection{Procedure}

Participants were tested during a management training programme. All were given feedback on their results. Furthermore those who worked with the target person also evaluated them on the EQi. Efforts were made to get full 360 data such that the target person (who completed all the measures) was evaluated by the boss (superior), 
peers, reports (subordinates) and clients. Inevitably these varied greatly between individuals both in terms of the number of people who completed the observer version of the questionnaire but their specific role with respect to the target person. For the purposes of this study the observer ratings were combined.

\section{Results}

\subsection{Statistical Analyses}

We used four statistical analyses in this paper to explore fist the self-report data, then the observer data. First, we used factor analysis to look at the structure of the 11 dark-side traits from the HDS. Second, we correlated the EI scores with the PD factors. Third, we did multiple regressions with the EI scores as the criteria variable and gender and the eleven PD scores as predictor variables. Fourth, we used analysis of variance to explore self vs other ratings of EI. Finally we repeated the regressions but this time using the observer ratings of the participants' EI scores.

\subsection{Self-Report Data}

First, given the imbalance between males and females in this sample a MANOVA was run comparing the sexes on the 11 HDS scores and the five EQi scores. Neither was statistically significant.

Next, the eleven HDS scales were subjected to a Promax and then Varimax rotated factor analysis. The result of both analyses was a three-factor solution almost identical to that found by Furnham \& Trickey (2011) who analysed the data on 18,366 adults. These were similarly labelled Moving against people (Cluster B), Moving away from people (Cluster A) and Diligent (Cluster C) scores on the items loading on the same factor were then aggregated so providing three scores per individual.

Then the five factors of the EQi measure were subjected to similar factor analysis, using both orthogonal and oblique rotations. In both cases a single factor emerged with all scales loading on the single factor. However for comparison with other studies using the EQi domain scores further analysis will be done on the total score and the various subscale scores.

The three higher order HDS scales were then correlated with the five EQi scales. Table 1 shows that Factor 1 (Moving again people) was significantly negatively correlated with stress, while Factor 2 (Moving away from people) was significantly negatively correlated with three of the five EQi scales (intrapersonal, interpersonal, and mood).

Six, step-wise multiple regressions were then computed with the Total EI score and the five subscales as the criterion variable and sex, and the eleven HDS scales as the predictor variables. Five regressions were significant: four HDS scales were significant predictors of the total EI score: Paranoid positive and Avoidant, Schizoid and Obsessive negative. They accounted for eight per cent of the variance. A similar result occurred for the Intrapersonal factor. The regression that accounted for most of the variance (16\%) was the Interpersonal factor and it showed that higher Schizoid and Narcissistic scores were associated with low Interpersonal intelligence scores.

Table 1. Correlations between the EI and HDS factors.

\begin{tabular}{|c|c|c|c|c|c|c|c|c|}
\hline & & IA & IE & SM & A & M & 1 & 2 \\
\hline 1 & Intrapersonal (IA) & & & & & & & \\
\hline 2 & Interpersonal (IE) & $0.27^{* *}$ & & & & & & \\
\hline 3 & Stress Man, (SM) & 0.02 & $0.19^{*}$ & & & & & \\
\hline 4 & Adaptability (A) & 0.07 & 0.10 & 0.02 & & & & \\
\hline 5 & Mood (M) & $0.34^{* *}$ & $0.64^{* *}$ & $0.13^{*}$ & 0.08 & & & \\
\hline 6 & Factor $1(1)$ & 0.09 & 0.04 & $-0.14^{*}$ & 0.04 & 0.05 & & \\
\hline 7 & Factor 2 (2) & $-0.12^{*}$ & $-0.30^{* * *}$ & -0.09 & -0.07 & $-0.31^{* *}$ & $-0.20^{* *}$ & \\
\hline 8 & Factor 3 (3) & -0.02 & 0.06 & 0.01 & 0.01 & -0.09 & 0.00 & 0.00 \\
\hline
\end{tabular}

Note: ${ }^{* *} p<0.01,{ }^{*} p<0.05$. 
The only factor which predicted the stress subscale was sex with females scoring higher than males. With the Mood subscale as the criterion variable the regression was significant with four HDS scales all with similar beta loadings (Borderline, Avoidant, Schizoid and Narcissistic. Looking across the six regressions it seemed that three HDS scales were most commonly associated with low EI scales: Avoidant, Schizoid and Narcissistic.

Finally three multiple step-wise regressions were computed, this time with the three factor scores resulting from the analysis shown in Table 2 as the criteria variables and the five EI subscale scores as predictor variables. Only one was significant that for the second factor (Moving Away from People), $F(6,240)=5.33, p<0.001$. It showed the higher the score on this Cluster A measure of the participants, the lower their Mood scale (beta $=$ $-0.20, t=2.45, p<0.01$ ) and their Interpersonal scale (beta $=-0.16, t=2.05, p<0.05$ ).

\subsection{Observer Data}

Table 3 shows the self and other scores as well as $t$-test results for each analysis. Three things are noticeable from these data. First, nearly all (16 out of 21) analyses showed a significant difference all in the same direction. Overall participants thought that they were more emotionally intelligent than did observers. The only exception was the Interpersonal total scale and subscale scores where the lack of significant difference seems mainly attributable to the participants giving slightly below average scores. Second, participants tended to give themselves scores between a third and a half of a $S D$ above the mean while observers gave scores one of two points above or below the mean of 100 . Third, in nearly all instances the $S D$ of the observers were lower than that of the estimates of the participants.

Next, the fifteen factors were subjected to a variety of factor analyses with different rotations. The factor model of the EQi was not confirmed. Then the five subscale scores for the observer data was computed, again for comparison processes. They were inter-correlated at around $r=0.25$ to $r=0.35$. The five subscale scores were first regressed onto the Total Other Estimated EQ score. This narrowly missed significance $(F(5,206)=$ 2.09, $p=0.068$ ).

A series of regressions were then computed similar to those reported in Table 4 however this time the criteria variable was the observer rather than the self-reported scores on the EQi. These are shown in Table 5. So the EQi observer scores were regressed onto the dark side PDs.

Four of the six regressions were significant. High scores on Dependent PD predicted low Intrapersonal intelligence; High scores on Schizoid and Dependent but low scores on Obsessive predicted low Interpersonal intelligence; high scores on Borderline and Schizotypal predicted low Stress management; while low scores on Schizoid and high scores on Anti-social predicted high Mood management.

Table 2. Means, SDs and factor analytic results.

\begin{tabular}{rcccccc}
\hline & Disorder & Mean & SD & \multicolumn{3}{c}{ Factor analytic results } \\
\hline 1 & Borderline & 55.93 & 25.74 & 0.01 & $\mathbf{0 . 7 1}$ & 0.04 \\
2 & Paranoid & 59.14 & 27.26 & 0.44 & $\mathbf{0 . 5 7}$ & 0.14 \\
3 & Avoidant & 53.03 & 26.13 & -0.21 & $\mathbf{0 . 6 2}$ & 0.39 \\
4 & Schizoid & 57.86 & 27.15 & -0.10 & $\mathbf{0 . 7 4}$ & -0.21 \\
5 & Passive-aggressive & 53.96 & 29.53 & -0.20 & $\mathbf{0 . 5 6}$ & 0.42 \\
6 & Narcissistic & 56.92 & 28.68 & $\mathbf{0 . 7 3}$ & -0.01 & 0.14 \\
7 & Anti-social & 51.83 & 27.47 & $\mathbf{0 . 7 3}$ & 0.17 & -0.24 \\
8 & Histrionic & 52.26 & 27.29 & $\mathbf{0 . 7 1}$ & -0.31 & -0.11 \\
9 & Schizotypal & 53.51 & 29.44 & $\mathbf{0 . 7 2}$ & 0.08 & 0.18 \\
10 & Obsessive & 57.45 & 28.51 & 0.12 & 0.09 & $\mathbf{0 . 6 2}$ \\
11 & Dependent & 57.26 & 28.50 & -0.10 & -0.01 & $\mathbf{0 . 8 0}$ \\
& & & Eigenvalue & $\mathbf{2 . 4 1}$ & $\mathbf{2 . 2 0}$ & $\mathbf{1 . 5 6}$ \\
\hline
\end{tabular}


Table 3. Self and other-rated EQi scores.

\begin{tabular}{|c|c|c|c|c|c|c|}
\hline & \multicolumn{2}{|c|}{ Self } & \multicolumn{2}{|c|}{ Other } & \multicolumn{2}{|c|}{$\mathrm{t}$} \\
\hline & $X$ & $S D$ & $X$ & $S D$ & Difference & \\
\hline Intrapersonal total & 103.58 & 17.37 & 99.79 & 8.64 & 5.80 & $4.79^{* * *}$ \\
\hline IA1. Self-regard & 106.43 & 9.20 & 100.63 & 7.83 & 5.79 & $9.14^{* * *+}$ \\
\hline IA2. Self-awareness & 102.18 & 11.91 & 96.92 & 8.74 & 5.26 & $4.29^{* * * *}$ \\
\hline IA3. Assertiveness & 106.39 & 12.78 & 101.92 & 8.73 & 4.47 & $5.36^{* * *+}$ \\
\hline IA4. Independence & 105.77 & 12.73 & 99.81 & 8.76 & 5.96 & $6.83^{* * * *}$ \\
\hline IA5. Self-actual & 104.39 & 10.51 & 98.62 & 8.68 & 5.77 & $6.67^{* *}$ \\
\hline Interpersonal total & 98.22 & 11.82 & 97.96 & 10.48 & 0.26 & 0.29 \\
\hline IE1. Empathy & 98.46 & 12.71 & 97.91 & 8.48 & 0.56 & 0.67 \\
\hline IE2. Social responsibility & 99.45 & 11.91 & 97.99 & 11.73 & 1.48 & 1.69 \\
\hline IE3. Interpersonal relations & 97.65 & 12.53 & 98.79 & 9.12 & -1.13 & 1.49 \\
\hline Stress management total & 105.56 & 11.23 & 102.67 & 6.99 & 3.29 & $4.58^{* *}$ \\
\hline S1. Stress tolerance & 108.55 & 10.38 & 102.67 & 6.99 & 5.58 & $7.69^{* * *+}$ \\
\hline S2. Impulse control & 101.80 & 12.41 & 101.53 & 7.91 & 0.27 & 0.39 \\
\hline Adaptability & 107.58 & 13.81 & 102.29 & 7.42 & 5.29 & $7.36^{* * *}$ \\
\hline A1. Reality testing & 105.67 & 10.87 & 102.87 & 10.87 & 2.82 & $3.90^{* * * *}$ \\
\hline A2. Flexibility & 107.80 & 11.64 & 101.32 & 11.42 & 6.48 & $8.07^{* * *+}$ \\
\hline A3. Problem solving & 105.32 & 10.35 & 101.68 & 6.73 & 3.03 & $5.19^{* *}$ \\
\hline General Mood & 104.54 & 10.16 & 98.55 & 10.53 & 5.57 & $7.98^{* * * *}$ \\
\hline GM1. optimism & 104.84 & 9.90 & 99.40 & 7.53 & 5.44 & $7.91^{* * * *}$ \\
\hline GM2. Happiness & 103.89 & 10.84 & 98.92 & 8.80 & 4.96 & $7.03^{* * *+}$ \\
\hline Total & 104.54 & 17.23 & 100.48 & 7.74 & 4.06 & $3.45^{* * *+}$ \\
\hline
\end{tabular}

Table 4. Results of the regression with EI total and subscale scores as the criterion (independent) variables and the PDs (dependent) variables as the predictor.

\begin{tabular}{|c|c|c|c|c|c|c|c|c|c|c|c|c|c|}
\hline & & \multicolumn{2}{|c|}{ Total } & \multicolumn{2}{|c|}{ Intrapersonal } & \multicolumn{2}{|c|}{ Interpersonal } & \multicolumn{2}{|c|}{ Stress management } & \multicolumn{2}{|c|}{ Adaptability } & \multicolumn{2}{|c|}{ Mood } \\
\hline & & Beta & $t$ & Beta & $t$ & Beta & $t$ & Beta & $t$ & Beta & $t$ & Beta & $t$ \\
\hline & Gender & 0.05 & 0.76 & 0.08 & 1.35 & 0.04 & 0.67 & 0.20 & $3.19^{* *}$ & -0.02 & -0.33 & 0.01 & 0.10 \\
\hline 1 & Borderline & -0.02 & 0.28 & 0.05 & 0.65 & 0.03 & 0.37 & -0.10 & -1.44 & -0.12 & -1.67 & -0.16 & $-2.24^{*}$ \\
\hline 2 & Paranoid & 0.17 & $2.32^{*}$ & 0.18 & $2.39^{*}$ & 0.01 & 0.18 & -0.06 & -0.76 & 0.08 & 1.04 & -0.02 & -0.32 \\
\hline 4 & Schizoid & -0.15 & $2.10^{*}$ & -0.10 & -1.35 & -0.38 & $-5.67^{* * *}$ & -0.11 & -1.48 & 0.01 & 0.14 & -0.17 & $-2.40^{*}$ \\
\hline 5 & Passive-aggressive & -0.08 & 1.00 & -0.12 & -1.48 & -0.04 & -0.54 & 0.09 & 1.14 & -0.03 & -0.35 & 0.04 & 0.46 \\
\hline 6 & Narcissistic & -0.16 & $2.15^{*}$ & -0.14 & -1.77 & -0.16 & $-2.18^{*}$ & -0.06 & -0.76 & 0.04 & 0.49 & -0.15 & $-2.03^{*}$ \\
\hline 7 & Anti-social & 0.07 & 0.95 & 0.11 & 1.43 & 0.01 & 0.15 & 0.01 & 0.15 & -0.07 & -0.85 & 0.13 & 1.67 \\
\hline 8 & Histrionic & 0.13 & 1.54 & 0.13 & 1.63 & 0.12 & 1.49 & 0.02 & 0.27 & -0.12 & -1.44 & 0.00 & 0.01 \\
\hline 9 & Schizotypal & -0.10 & 1.24 & -0.09 & -1.20 & 0.02 & 0.23 & -0.12 & -1.58 & 0.17 & $2.09^{*}$ & 0.04 & 0.56 \\
\hline 10 & Obsessive & 0.14 & $2.02^{*}$ & 0.15 & $2.17^{*}$ & 0.06 & 0.92 & -0.07 & -0.93 & -0.08 & -1.14 & -0.01 & 0.12 \\
\hline 11 & Dependent & -0.09 & -0.34 & -0.05 & -0.73 & 0.02 & 0.26 & 0.02 & 0.32 & 0.06 & 0.85 & -0.02 & -0.24 \\
\hline & $F(12,246)$ & \multicolumn{2}{|c|}{$2.76^{* * *}$} & \multicolumn{2}{|c|}{$2.53^{* *}$} & \multicolumn{2}{|c|}{$5.03^{* * *}$} & \multicolumn{2}{|c|}{$2.41^{* * *}$} & \multicolumn{2}{|c|}{1.06} & \multicolumn{2}{|c|}{$3.57^{* * *}$} \\
\hline & Adjusted $\mathrm{R}^{2}$ & \multicolumn{2}{|c|}{0.08} & \multicolumn{2}{|c|}{0.07} & \multicolumn{2}{|c|}{0.16} & \multicolumn{2}{|c|}{0.06} & \multicolumn{2}{|c|}{0.00} & \multicolumn{2}{|c|}{0.11} \\
\hline
\end{tabular}

Note: ${ }^{* * *} p<0.001,{ }^{* *} p<0.01,{ }^{*} p<0.05$. 
Table 5. Results of the regression with EQ-360 and subscale scores as the criterion (independent) variables and the PDs (dependent) variables as the predictor.

\begin{tabular}{|c|c|c|c|c|c|c|c|c|c|c|c|c|c|}
\hline & & \multicolumn{2}{|c|}{ Total } & \multicolumn{2}{|c|}{ Intrapersonal } & \multicolumn{2}{|c|}{ Interpersonal } & \multicolumn{2}{|c|}{ Stress Management } & \multicolumn{2}{|c|}{ Adaptability } & \multicolumn{2}{|c|}{ Mood } \\
\hline & & Beta & $t$ & Beta & $t$ & Beta & $t$ & Beta & $t$ & Beta & $t$ & Beta & $t$ \\
\hline & Gender & -0.06 & 0.65 & 0.02 & 0.27 & 0.00 & 0.00 & -0.08 & 1.15 & -0.04 & 0.57 & -0.11 & 1.71 \\
\hline 1 & Borderline & 0.00 & 0.10 & 0.10 & 1.31 & 0.12 & 1.52 & -0.19 & $-2.52^{* *}$ & -0.02 & 0.23 & -0.04 & 0.57 \\
\hline 2 & Paranoid & -0.02 & 0.23 & -0.03 & 0.40 & -0.05 & 0.54 & -0.05 & 0.60 & 0.04 & 0.49 & -0.11 & 1.36 \\
\hline 3 & Avoidant & -0.07 & 1.01 & -0.13 & 1.58 & 0.06 & 0.72 & -0.02 & 0.20 & -0.13 & 1.51 & -0.10 & 1.26 \\
\hline 4 & Schizoid & -0.14 & 1.86 & -0.14 & 1.76 & -0.24 & $-3.28^{* *}$ & -0.05 & 0.64 & 0.02 & 0.23 & -0.24 & $-3.17^{* *}$ \\
\hline 5 & Passive-aggressive & 0.03 & 0.93 & 0.03 & 0.35 & 0.07 & 0.81 & 0.00 & 0.01 & 0.01 & 0.13 & 0.05 & 0.54 \\
\hline 6 & Narcissistic & -0.02 & 0.22 & 0.00 & 0.11 & -0.13 & 1.57 & 0.00 & 0.02 & -0.03 & 0.33 & -0.02 & 0.19 \\
\hline 7 & Anti-social & 0.05 & 0.18 & 0.05 & 0.57 & 0.03 & 0.30 & 0.00 & 0.05 & -0.05 & 0.63 & 0.16 & $1.97^{*}$ \\
\hline 8 & Histrionic & 0.07 & 0.80 & 0.09 & 1.05 & 0.16 & 1.82 & -0.07 & 0.76 & -0.03 & 0.25 & 0.13 & 1.49 \\
\hline 9 & Schizotypal & -0.15 & 1.75 & -0.10 & 1.24 & -0.13 & 1.57 & -0.21 & $-2.57^{* *}$ & -0.13 & 1.47 & -.10 & 1.27 \\
\hline 10 & Obsessive & 0.04 & 0.53 & 0.03 & 0.33 & 0.15 & $1.96^{*}$ & 0.09 & 1.24 & 0.01 & 0.18 & 0.05 & 0.61 \\
\hline 11 & Dependent & -0.14 & 1.89 & -0.16 & $-2.80^{*}$ & -0.17 & $2.24^{*}$ & -0.13 & 1.73 & -0.13 & 1.69 & -0.02 & 0.23 \\
\hline & $F(12,246)$ & \multicolumn{2}{|c|}{1.51} & \multicolumn{2}{|c|}{$1.78^{*}$} & \multicolumn{2}{|c|}{$1.87^{*}$} & \multicolumn{2}{|c|}{$2.98^{* * * *}$} & \multicolumn{2}{|c|}{1.26} & \multicolumn{2}{|c|}{$3.56^{* *}$} \\
\hline & Adjusted $\mathrm{R}^{2}$ & \multicolumn{2}{|c|}{0.03} & \multicolumn{2}{|c|}{0.04} & \multicolumn{2}{|c|}{0.05} & \multicolumn{2}{|c|}{0.10} & \multicolumn{2}{|c|}{0.02} & \multicolumn{2}{|c|}{0.13} \\
\hline
\end{tabular}

Note: ${ }^{* * *} p<0.001, \stackrel{* *}{p} p<0.01,{ }^{*} p<0.05$.

\section{Discussion}

There were two different aspects to this study. The first was the difference between self- and other rated dimensions of EI. There is now an extensive literature on the superiority effect, leniency bias or having a sense of relative superiority over others. This essentially illusory superiority is a cognitive bias that causes people to overestimate their positive and to underestimate their negative qualities, relative to others. This is evident in a variety of areas including intelligence, performance on many tasks or tests, and personality traits (Furnham, 2008). In this sense there is an extensive literature that has shown that people think they are above average on characteristics ranging from careful driving to altruism. Further, because observers are not prone to this effect, one may expect a difference between self- and other-reports such that self-reports over-estimate positive traits. Equally this could be seen as evidence of faking (Grubb \& McDaniel, 2007; Hartman \& Grubb, 2011).

This idea was supported by the data. Table 3 shows that of the 21 self-other differences, participants rated themselves significantly higher on all but five. The biggest differences were on flexibility, independence and self-regard. Participants gave themselves highest rating for stress tolerance. There are two further interesting features of this part of the study. The first is the exception of the Interpersonal EQi total and subscale scores where there was no difference between self- and other-reports possibly because of the fact that the participants scored themselves below average on this scale. This component and subscale scores indicate social adeptness, the ability to understand others, and to interact and relate well to people. It is interesting but unclear why this sample scored themselves consistently lower on this component and scales, particularly on interpersonal relations. The second is the size of the difference which is, on average, around a third of a standard deviation.

The second feature of this study was the relationship between the PDs and EI. It may be expected that if scores on these measures were significantly related, they would be negative as EI is generally considered a highly desirable trait and the PDs, by definition, undesirable. There were three analyses which spoke to this issue. The first is in Table 1 which shows correlation between the higher order factors of both measures. In all 4 of the 15 correlations were significant and all were negative. Two were $r=0.30$ or above, which suggests little relationship between the two measures.

However we all did two regression studies with the five EQi factors plus the total score as the criteria variables and the eleven PDs as the predictor variables. This was done both for self-reported (Table 4) as well as 
other-reported (Table 5) EQi scores. The results were reasonably consistent in showing that Avoidant, Schizoid and Narcissistic PD was clearly negatively associated with EI (total, Interpersonal and Mood). This certainly makes sense in terms of the constructs and the previous literature.

Perhaps the most interesting finding from Table 4 was the significant positive beta weights. In two regressions (total and Interpersonal) Paranoid PD and Obsessive PD was positively associated with the scores while in one (Adaptation) Schizotypal disorder was positively associated. The question is why this should be? It maybe that the shrewd/mistrustful/paranoid person has learnt to be highly sensitive to the behavior of others because of the threat they believe others might pose. The Intrapersonal EI score includes subscales like assertiveness and independence, which could be seen as related to some aspects of paranoia. This interpersonal vigilance and sensitivity may indeed make them more emotionally intelligent in terms of their observation/awareness skills. It is less difficult to see why Obsessiveness as manifest in diligence and perfectionism may also be related to (self-reported) EI. Again this relates to their attentiveness to the (work) behavior of others, which can be seen as positive, though the critical behaviours associated with it are not. Finally, Schizotypal scores were related to EQi adaptation which is about reality testing, flexibility and problem solving. It may be that the unconventional ("think-outside-the-box") thinking is related to those with high imaginative/eccentric/schizotypal scores because they are seen to be creative.

When the other-reported EI scores were the criterion variables, the patterns were very different. First, fewer of the regressions were significant and five of the PDs (Paranoid, Avoidant, Passive Aggressive, Narcissistic and Histrionic) were not associated with any of EI factors. Second, in two regressions Schizoid was negatively associated with EI and Dependent in two others. Only two of the beta's were positive: obsessive was related positively to Intrapersonal intelligence and anti-social PD to Mood.

Like all others this study had limitations. We were unable to obtain data on the participant's age and job experience which might have been relevant to their individual scores. More importantly we were unable to examine the internal reliability of the 360 "other" reports which might mean that the data were unstable. There is also the possibility of dissimulation.

\section{References}

Aguirre, F., Sergi, M., \& Levy, C. (2008). Emotional Intelligence and Social Functioning in Persons with Schizotypy. Schizophrenia Research, 104, 255-264. http://dx.doi.org/10.1016/j.schres.2008.05.007

Bar-On, R. (2004). The Bar-On Emotional Quotient Inventory (EQ-i): Rationale, Description and Psychometric Properties. In G. Geher (Ed.), Measuring Emotional Intelligence: Common Ground and Controversy (pp. 115-145). Hauppauge, NY: Nova Science.

Bar-On, R. (2006). The Bar-On Model of Emotional-Social Intelligence (ESI). Psicothema, 18, 13-25.

Butler, C. J., \& Chinowsky, P. S. (2006). Emotional Intelligence and Leadership Behaviour in Construction Executives. Journal of Management Engineering, 22, 119-125. http://dx.doi.org/10.1061/(ASCE)0742-597X(2006)22:3(119)

Day, A. L., Therrien, D. L., \& Carroll, S. A. (2005). Predicting Psychological Health: Assessing the Incremental Validity of Emotional Intelligence beyond Personality, Type A Behaviour, and Daily Hassles. European Journal of Personality, 19, 519-536. http://dx.doi.org/10.1002/per.552

Dawda, D., \& Hart, S. D. (2000). Assessing Emotional Intelligence: Reliability and Validity of the Bar-On Emotional Quotient Inventory (EQ-i) in University Students. Personality and Individual Differences, 28, 797-812. http://dx.doi.org/10.1016/S0191-8869(99)00139-7

De Fruyt, F., De Clercqm B., Miley, J., Rolland, J. P., Jung, S. C., Taris, R. et al. (2009). Assessing Personality at Risk in Personnel Selection and Development. European Journal of Personality, 23, 51-69. http://dx.doi.org/10.1002/per.703

Demetrovics, K. (2010) The Role of Emotional Intelligence in Addiction Disorders. Psychiatric Hung, 25, 503-524.

Dotlich, D., \& Cairo, P. (2003). Why CEOs Fail. New York: Jossey Bass.

Fico., J., Hogan, R., \& Hogan, J. (2000) Interpersonal Compass Manual and Interpretation Guide. Tulsa, OK: Hogan Assessment Systems.

Furnham, A. (2006). Personality Disorders and Intelligence. Journal of Individual Differences, 27, 42-45. http://dx.doi.org/10.1027/1614-0001.27.1.42

Furnham, A., (2008). Personality and Intelligence at Work. London: Routledge. http://dx.doi.org/10.4324/9780203938911

Furnham, A., \& Crump, J. (2005). Personality Traits, Types and Disorders. European Journal of Personality, 19, $167-184$. http://dx.doi.org/10.1002/per.543 
Furnham, A., \& Trickey, G. (2011). Sex Differences in the Dark Side Traits. Personality and Individual Differences, 50, 517-522. http://dx.doi.org/10.1016/j.paid.2010.11.021

Gardner, K., \& Qualter, P. (2009). Emotional Intelligence and Borderline Personality Disorder. Personality and Individual Differences, 47, 94-98. http://dx.doi.org/10.1016/j.paid.2009.02.004

Grubb, W. L., \& McDaniel, M. A. (2007). The Fakability of Bar-On’s Emotional Quotient Inventory Short Form: Catch Me If You Can. Human Performance, 20, 43-59. http://dx.doi.org/10.1080/08959280709336928

Hartman, N. S., \& Grubb III, W. L. (2011). Deliberate Faking on Personality and Emotional Intelligence Measures. Psychological Reports, 108, 120-138. http://dx.doi.org/10.2466/03.09.28.PR0.108.1.120-138

Hogan, R., \& Hogan, J. (1997). Hogan Development Survey. Tulsa, Oklahoma: Hogan Assessment Systems.

Hogan, R., \& Hogan, J. (2001). Assessing Leadership: A View from the Dark Side. International Journal of Selection and Assessment, 9, 40-51. http://dx.doi.org/10.1111/1468-2389.00162

Hyler, S. (1994) PDQ-4 and PDQ-4+: Instructions for use. Unpublished Manuscript: Columbia University.

Khoo, H., \& Burch, G. (2008). The "Dark Side” of Leadership Personality and Transformational Leadership. Personality and Individual Differences, 44, 86-97. http://dx.doi.org/10.1016/j.paid.2007.07.018

Leible, T., \& Snell, W. (2004). Borderline Personality Disorder and Multiple Aspects of Emotional Intelligence. Personality and Individual Differences, 37, 393-404. http://dx.doi.org/10.1016/j.paid.2003.09.011

Martins, A., Ramalho, N., \& Morin E. (2010). A Comprehensive Meta-Analysis of the Relationship between Emotional Intelligence and Health. Personality and Individual Differences, 49, 554-564. http://dx.doi.org/10.1016/j.paid.2010.05.029

Oldham,J., \& Morris, R. (1991). Personality Self Portrait. New York: Bantam Books.

Parker, J. D., Taylor, G. J., \& Bagby, R. M. (2001). The Relationship between Emotional Intelligence and Alexithymia. Personality and Individual Differences, 30, 107-115. http://dx.doi.org/10.1016/S0191-8869(00)00014-3

Petrides, K. V., Niven, L., \& Mouskounti, T. (2006). The Trait Emotional Intelligence of Ballet Dancers and Musicians. Psicothema, 18, 101-107.

Petrides, K. V., Pérez-González, J.-C., \& Furnham, A. (2007). On the Criterion and Incremental Validity of Trait Emotional Intelligence. Cognition and Emotion, 21, 26-55. http://dx.doi.org/10.1080/02699930601038912

Petrides, K. V., Hudry, K., Michalaria, G., \& Swami, V. (2011). A Comparison of the Trait Emotional Intelligence Profiles of Individuals with and without Asperger Syndrome. Autism, 15, 671-682. http://dx.doi.org/10.1177/1362361310397217

Rolland, J.-P., \& DeFruyt, F. (2003). The Validity of FFM Personality Dimensions and Maladaptive Traits to Predict Negative Affect at Work. European Journal of Personality, 17, 101-121. http://dx.doi.org/10.1002/per.485

Snell, W. (1999). The Multidemional Emotional Awareness Questionnaire (Unpublished Data).

Singh, K., Arteche, A., \& Holder, M. (2011) Personality Factors and Psychopathy, Alexithymia and Stress. Asian Journal of Psychiatry, 4, 35-40. http://dx.doi.org/10.1016/j.ajp.2011.01.003

Vernon, P. A., Villani, V. C., Schermer, J. A., \& Petrides, K. V. (2008). Phenotypic and Genetic Associations between the Big Five and Trait Emotional Intelligence. Twin Research and Human Genetics, 11, 524-530. http://dx.doi.org/10.1375/twin.11.5.524

Zeidner, M., Matthews, G., \& Roberts, R. (2004). Emotional Intelligence in the Workplace: A Critical Review. Applied Psychology, 33, 371-399. http://dx.doi.org/10.1111/j.1464-0597.2004.00176.x 